\title{
Publisher Correction: Towards an ecosystem model of infectious disease
}

James M. Hassell (D, Tim Newbold (D), Andrew P. Dobson (1D, Yvonne-Marie Linton, Lydia H. V. Franklinos, Dawn Zimmerman and Katrina M. Pagenkopp Lohan

Correction to: Nature Ecology \& Evolution https://doi.org/10.1038/s41559-021-01454-8, published online 17 May 2021.

In the version of this Perspective originally published, the numbering of references 53 and 55-98 was incorrect in the reference list. Reference 98 should have been 53, reference 53 should have been 55 and references $55-97$ should have been 56-98, respectively. Additionally, in the final column of Table 1, the citation of reference 48 should have been a citation of reference 46 . These errors have now been corrected.

Published online: 26 May 2021

https://doi.org/10.1038/s41559-021-01495-z

This is a U.S. government work and not under copyright protection in the U.S.; foreign copyright protection may apply 2021 